\title{
Sibling Relationships of Children With Down Syndrome: Perspectives of Mothers, Fathers, and Siblings
}

\author{
Monica Cuskelly and Pat Gunn \\ Fred and Eleanor Schonell Special Education Research Centre \\ University of Queensland
}

\begin{abstract}
Fifty-four siblings of children with Down syndrome and their parents and an individually matched group of comparison children and parents provided data about the quality of sibling relationships. There were no group differences in parental reports, but siblings of children with Down syndrome reported less unkindness and, if in a same-sex dyad, more empathy than did comparison children. There were differences between same-sex and opposite-sex dyads regarding avoidance and frequency of sibling positive and negative interactions. There were no group or sex differences in children's reports of their interactions with parents or contribution to household chores. Siblings of a child with Down syndrome participated in more caregiving activities. Caregiving was associated with empathy and involvement on the relationship questionnaire.
\end{abstract}

When parents have an implicit or explicit plan for the future of their child with mental retardation after their own death or incapacitation, that plan is most likely to identify a sibling as the key successor (Bigby, 1996). It would seem that sibling relationships have long-term implications for children with Down syndrome in Western societies, as they currently look forward to longer lives (Steele, 1996), probably within a smaller family than in the past (Australian Bureau of Statistics, 2001; Gath \& McCarthy, 1996), so that care and personal relationships are not shared widely among siblings.

Whether a brother or a sister is more likely to undertake the care and support of a sibling has been the focus of several studies. The pattern of a sibling relationship may change over time, but it develops through the life course from childhood foundations. During childhood, females are involved in more child-care and home responsibilities than are males, though there may be a recent trend for brothers to undertake more child- care if the sibling has a disability (see review by Damiani, 1999). Sisters generally provide more support than brothers for adult siblings (Akiyama, Elliot \& Antonucci, 1996; Cicirelli, 1996), and if the sibling is an older adult with mental retardation, mothers are more likely to nominate a sister as the sibling most involved with that adult (Seltzer, Begun, Seltzer, \& Krauss, 1991). These findings have upheld the femaleness principle, which proposes that gender differences in personal relationships reflect the femaleness of the dyad, with most closeness and support in sister-sister and least in brother-brother dyads. Akiyama et al. (1996) proposed that the principle applied especially to the instrumental provision of support, as their community-based study found that support from women to older adults was not necessarily associated with psychological closeness. On the other hand, when the sibling was an adult with mental retardation, the femaleness principle seemed to extend beyond the provision of support into the affective quality of the sibling rela- 
tionship (Orsmond \& Seltzer, 2000). Sisters not only provided more care but felt closer to their sibling than brothers did. Findings with brothers supported a modified form of the sex commonality principle, an alternative to the femaleness principle. It posits that same-sex dyads are closer than cross-sex dyads and have more intense feelings, positive and negative, for one another (Akiyama et al., 1996). Men with brothers who have mental retardation had high positive feelings about their sibling but few negative feelings. Men showed the opposite pattern towards sisters with mental retardation, but the pattern for women was the same for brothers and sisters. These findings relate to adults who grew up in a previous generation; whether they are typical of children growing up today is not known. In this study we investigated the influence of femaleness and sex commonality on the sibling relationships of children, including a group with Down syndrome.

Researchers have recognized the importance of considering the viewpoints of different members of the family in attempting to assess the qualities of sibling relationships. The closer viewpoints converge, the less likely are misunderstandings between family members. Some misunderstandings may result from parental failure to recognize negativity in a sibling relationship; some may lead to differential treatment of siblings, with attendant risks for the relationship. In this study, we investigated the perspectives of fathers, mothers, and siblings and considered their relationship to sibling interactions and children's contribution to family functioning. A tentative hypothesis was that children who perceived more negativity than did parents in their sibling relationships would report more negative sibling interactions during the day and lower participation in activities related to sibling caregiving.

Participants in the study were not only matched at the group level but also were individually matched. In addition, all the children with disabilities had Down syndrome with a moderate level of cognitive delay. Previous studies of the sibling relationships of children with intellectual disabilities have differed with respect to method of matching and composition of the group. This more rigorous design should limit confounding due to mixed disabilities and different levels of disability (Stoneman, 1989).

Participants in comparison families were matched to families of children with Down syndrome with respect to child and family character- istics: relative age, chronological age (CA) and sex of each child in a dyad, and SES and size of the dyad's family. The age range was mid- to latechildhood, when children spend more time together and are better equipped than younger children to report on their own understandings (Epkins \& Dedman, 1999). Relative age in the sibling dyad was matched because it can influence sibling interactions (Stoneman, Brody, Davis, Crapps, \& Malone, 1991), and it allowed the investigation of a possible role-crossover effect for older siblings with Down syndrome (O'Connor \& Stachowiak, 1971).

In addition to questionnaires about the sibling relationship, information was obtained by telephone about the child's view of daily interactions with parents and sibling. These reports provided an alternative access to the children's view of sibling relationships and allowed us to gain information about the children's participation in family chores and caregiving.

The questions considered in the study were:

1. Are perspectives of family members consistent regarding positive and negative qualities of sibling relationships?

2. Do these perspectives differ by group and sex or age and birth order of the siblings?

3 . Is there an effect of sex commonality or femaleness on sibling relationships?

4. Do household or caregiving responsibilities vary with birth order, sex, or group and are these related to perspectives of sibling relationships?

\section{Method}

\section{Participants}

Families with a child who has Down syndrome. Criteria established prior to the recruitment of families with a child who has Down syndrome were as follows: two parents resided in the home; each family had only one child with Down syndrome; no other child in the family had a disability; the study sibling would be the sibling nearest in age to the child with Down syndrome and within 4.5 years of that child; the sibling was between 7 and 14 years of age. Another criterion was that the child with Down syndrome would be older than 5.5 years but younger than 18 years. If the 4.5 years difference in dyadic age were to be accepted as the minimum and maximum sibling ages, the age range for the child with Down syn- 
drome would have been from 2.5 years to 18.5 years. The restriction in age range brought it closer to the sibling range, and the higher minimum age helped to ensure that the child's disability was apparent in his or her everyday functioning so that siblings would be aware of their younger brother or sister's delay beyond infancy. Because the extent of sibling participation in domestic chores and caregiving may be dependent on the competence of the child with disabilities (Stoneman et al., 1991), care was taken to ensure that the children with Down syndrome showed a moderate level of cognitive delay, with none severely delayed in adaptive competence.

Families living in South East Queensland who had a child with Down syndrome were identified. Because of the nature of our contacts and our experience in recruiting birth cohorts, it is believed that almost all children with Down syndrome living in this area would have been identified. One family refused and 54 families took part in the study.

The 54 siblings of a child with Down syndrome in the study comprised 14 girls older than their sister or brother with Down syndrome (mean $\mathrm{CA}=133.43$ months, standard deviation $[S D]=$ 25.66), 12 girls younger than their sister or brother with Down syndrome (mean CA $=131.67$ months; $S D=27.91$ ), 14 boys older than their sister or brother with Down syndrome (mean CA $=128.43$ months; $S D=20.21$ ), and 14 boys younger than their sister or brother with Down syndrome (mean CA $=125.36$ months; $S D=$ 20.77). Twelve girls had a sister with Down syndrome, and 16 boys had a brother with Down syndrome.

Comparison families. Comparison families were recruited from a number of sources, including nomination by other families in the study, letters to community organizations, and direct advertising placed on notice-boards. Children were matched on a case-by-case basis with the identified child in the Down syndrome families. Target children were matched as closely as possible on gender, age, and position in the family. Families were matched on number of children in the family and father's occupation. Children were matched for age, within 6 months, at the time of interview. Number in family was matched for families with four or fewer children. If families with a child who had Down syndrome were larger than this, they were considered matched if the comparison family had more than four children.
Position in families was considered matched if both children were the oldest or if both were not in the extreme first or last positions. Fathers' occupations were classified according to the system developed by Daniel (1983) for describing occupational status in Australia, and families were matched to within one level of this system. Highest status (professional) was allocated a rating of 1 and lowest status (unemployed), a rating of 9. No child/family failed to match on more than one of the matching characteristics. None of the comparison families had a child with a diagnosed disability. Characteristics for families with a child who had Down syndrome and comparison families were, respectively: number of children, means $=3.1$ (range $=2$ to 7 ) and 3.2 (range $=2$ to 10$)$; child's birth order, means $=2.0$ (range $=1$ to 6$)$ and 2.2 (range $=1$ to 7); father's occupation, means $=2.9($ range $=1$ to 5$)$ and 2.6 (range $=$ 1 to 6 ). The only significant demographic difference between the two groups concerned maternal employment, $\chi^{2}(1, N=107)=4.02, p<.05$. More comparison mothers worked either full- or part-time outside the home than did mothers of children with Down syndrome.

Of the 53 comparison children, 14 girls were older than a sister or brother (mean CA $=131.71$ months; $S D=27.55)$; 11 girls, younger than a sister or brother (mean CA = 127.3 months; $S D$ $=29.57) ; 14$ boys, older than a sister or brother (mean CA $=130.29$ months; $S D=22.26$ ); and 14 boys, younger than a sister or brother (mean $\mathrm{CA}=127.71$ months; $S D=24.17$ ). There were 12 sister-sister dyads and 11 brother-brother dyads. No comparison child could be found to match one of the younger sisters of a child with Down syndrome.

\section{Questionnaire}

The Sibling Inventory of Behavior (Schaefer \& Edgerton, 1981) has 28 items with four scales, Empathy (6 items), Involvement (7 items), Unkindness ( 9 items), and Avoidance (6 items). All items relate to the behavior of the focus child toward their brother or sister and ask the respondent to indicate how often the identified behavior takes place. A 5-point Likert scale is used, anchored by Never (1) and Always (5), with high scores indicating a high level of behavior. After examining Cronbach alpha and other measures of internal consistency for the study sample, we dropped 3 items from the Avoidance scale. Alpha values for the Empathy scale were $.82, .85$, and .84 for fa- 
ther, mother, and child ratings, respectively. The corresponding alpha values for Involvement were $.84, .83$, and .78; for Unkindness, .77, .82, and .74; and for the reduced Avoidance scale, .80, .76, and .77.

Telephone interviezes. Individual telephone interviews were conducted with children and mothers. These yielded scores for the child's involvement in activities related to care of the target sibling and for doing household chores. The interviewer used a series of prompt questions to determine whether the child had engaged in a particular activity that day. If an affirmative answer was received, the child (or mother) was asked whether the child had engaged in that activity alone or with another. The caregiving score was the number of caregiving activities the child engaged in with regard to the target brother or sister. One caregiving score was derived from child reports and another from mother reports. Children (and mothers) were then asked whether the child had helped his or her mother or father with chores that day. A list of 28 chores was read to the child (or mother), who confirmed whether or not each task had been undertaken. The responses provided one score for child and another for mother reports. Children were next asked 30 questions about sibling and parent behavior that day (10 questions about each person). These interaction data were collected only from the children. They were asked questions such as: Did you tease or annoy ___ (name of the sibling) today? Was your mother/father pleased with you today? The child's answers to these questions were recorded as yes or no, and a total was derived for positive and negative behaviors (a) performed by child and directed toward brother or sister, (b) performed by mother and directed toward child, and (c) performed by father and directed toward child.

\section{Procedure}

A female and a male interviewer visited all families at home. Mothers were interviewed by the female investigator and fathers, by the male investigator. Both parents completed the Sibling Inventory of Behavior questionnaire. The female interviewer usually visited on a second occasion to interview the child, but in some instances all interviews were conducted on the same day. Questions on the Sibling Inventory of Behavior were read to children by the female interviewer and their responses recorded.

There were four telephone interviews with the child and the mother following the completion of home interviews. These telephone calls were made on different days of the week over approximately a 4-week period, and at least one call was made on a weekend or a holiday. All information collected over the four calls was averaged to provide one score for each item. When more than one holiday was included in the telephone interview data, the information collected on those days was averaged and used as one data point.

\section{Results}

\section{Overall Analyses}

Pearson correlations and repeated measures MANOVAs were used in the following analyses. Significant MANOVA results were followed by univariate testing to determine the source of the effect. After significant ANOVA results, partial eta $(\eta), \eta^{2}=S S_{\text {effect }} /\left(S S_{\text {effect }}+S S_{\text {error }}\right)$ was used as a measure of strength of association. One outlier was excluded from the analyses.

Question 1. Do perspectives of family members agree regarding positive and negative qualities of sibling relationships?

This question was addressed by examining interrater correlations for each Sibling Inventory of Behavior scale (agreement regarding the order of ratings). The possibility of differences in rater means was investigated during the MANOVA analysis of group and sex effects on the ratings (see Question 2). We then used Tukey testing to determine which means were significantly different from each other.

Question 2. Do the perspectives of family members regarding sibling relationships differ by group and sex or age and birth order of the sibling?

Effects of group and sex were investigated for each scale in a MANOVA, with scores given by three raters as repeated measures. These effects were also examined in analyses of children's telephone reports of daily interactions. Scores for positive, then negative interactions, were repeated measures, and group and sex were independent variables. To determine whether sibling age or birth order was associated with ratings of the sibling relationship, we correlated these variables with the four Sibling Inventory of Behavior scale scores for each rater in turn. 
Question 3. Is there an effect of sex commonality or femaleness on sibling relationships?

Repeated measures analyses with Sibling Inventory of Behavior scores as dependent measures were again used. The independent variables were sex of sibling and sex commonality (children in dyad of same or different sex). The analysis was undertaken for each scale in turn.

Question 4. Do household or caregiving responsibilities vary with birth order, sex, or group, and are these related to perspectives of sibling relationships?

In one MANOVA, dependent measures were scores for caregiving and in another, scores for chores. Group and sex were independent factors. Because of the possibility of a role-crossover effect, further analyses of the caregiving and chores scores were conducted with group and relative age (whether older or younger than the sibling) as the two independent variables. Other issues related to birth order were addressed through comparing the number of first born versus other birth orders in children who scored highly for caregiving or chores.

\section{Rater Agreement on Sibling Inventory of Behavior Scales}

All correlations between mother and father ratings were significant, $p<.05$. Agreement between children and parents was lower, with least agreement on Avoidance (see Table 1). The four Sibling Inventory of Behavior scales were then analyzed for group and sex effects, with rater as the repeated measure. The only significant rater effect was on Avoidance, $F(1,318)=13.75, p<.001$. Tukey testing found ratings by mothers and fathers ( $M s=4.2$ and 4.3, respectively) significantly different, $p<.01$, from ratings by children $(M=$ 5.3). Significant group and sex effects on Sibling Inventory of Behavior scales are described below.

\section{Group and Sex Effects on Sibling Inventory of Behavior Ratings}

Mean Sibling Inventory of Behavior scores for each group and sex are shown in Table 2. Correlations between rating and sibling age and between rating and birth order were not significant for any rater.

\section{Empathy}

There was a significant effect on Empathy scores for group, $F(1,101)=4.22, p<.05$, and sex, $F(1,101)=5.88, p<.05$. Univariate testing found that the group effect was mainly due to scores by children, $F(1,101)=7.15, p<.01, \eta$ $=.26$. Scores were lower for the comparison group $(M=22.8, S D=3.96)$ than for siblings of children with Down syndrome $(M=24.7, S D=$ 4.36). The overall sex effect, however, did not reach a significant level when univariate analysis was undertaken of ratings given by children, mothers, and fathers.

\section{Involvement}

There were no significant effects of group, sex, or their interaction on Involvement scores. There was a significant interaction between rater and group, $F(2,202)=4.51, p<.05$, but univariate analysis did not find a significant group effect for any rater.

\section{Unkindness}

There was a significant effect of group on Unkindness scores, $F(1,102)=8.73, p<.01, \eta=$ .28 , and a trend towards significance for sex, $p=$ .063. Univariate analysis showed that the group effect was mainly due to children's scores, $F(1$, $102)=17.22, p<.001, \eta=.38$ and the effect of sex to scores given by fathers, $F(1,102)=6.43$, $p<.015, \eta=.24$. Children in the comparison group gave higher scores than did siblings of children with Down syndrome. Fathers gave higher scores to males than to females.

\section{Avoidance}

There were no significant effects for group, sex, or their interaction on Avoidance scores.

\section{Sex Commonality}

Multivariate analyses of variance were undertaken for each Sibling Inventory of Behavior scale. Dependent variables were Sibling Inventory of Behavior scores given by three raters, and independent variables were sex of sibling and sex commonality. The only significant effects were on Unkindness and Avoidance. On Unkindness, sex commonality was not a significant main effect but the interaction Sex $\times$ Sex Commonality was significant, $F(1,102)=5.33, p<.05$. On Avoidance, the only significant effect was for the interaction Rater $\times$ Sex $\times$ Sex Commonality, $F(2$, $204)=5.77, p<.01$. Univariate analysis showed that the Unkindness effect was mainly due to a trend to significance, $p=.05$, for the interaction 
Table 1. Sibling Inventory of Behavior (SIB) Score Correlations

\begin{tabular}{|c|c|c|c|c|}
\hline \multirow[b]{2}{*}{$\begin{array}{l}\text { SIB scale/ } \\
\text { Family member }\end{array}$} & \multicolumn{2}{|c|}{ Father } & \multicolumn{2}{|c|}{ Mother } \\
\hline & $\begin{array}{l}\text { Comparison } \\
\text { group }\end{array}$ & $\begin{array}{l}\text { Siblings } \\
\text { of DS child }\end{array}$ & $\begin{array}{l}\text { Comparison } \\
\text { group }\end{array}$ & $\begin{array}{l}\text { Siblings } \\
\text { of DS child }\end{array}$ \\
\hline \multicolumn{5}{|l|}{ Empathy } \\
\hline \multicolumn{5}{|l|}{ Father } \\
\hline Mother & .40 & .34 & & \\
\hline Child & .19 & .28 & .33 & .44 \\
\hline \multicolumn{5}{|l|}{ Involvement } \\
\hline \multicolumn{5}{|l|}{ Father } \\
\hline Mother & .58 & .50 & & \\
\hline Child & .43 & .42 & .38 & .35 \\
\hline \multicolumn{5}{|l|}{ Unkindness } \\
\hline \multicolumn{5}{|l|}{ Father } \\
\hline Mother & .57 & .48 & & \\
\hline Child & .36 & .16 & .50 & .29 \\
\hline \multicolumn{5}{|l|}{ Avoidance } \\
\hline \multicolumn{5}{|l|}{ Father } \\
\hline Mother & .30 & .57 & & \\
\hline Child & .22 & .03 & .03 & -.18 \\
\hline
\end{tabular}

Sex $\times$ Sex Commonality on children's ratings. Males with sisters tended to give higher scores than did males with brothers, $p=.075(M s=8.8$ $[S D=4.49]$ and $6.4[S D=5.20]$, respectively), whereas there was no significant difference between the ratings given by females to male or female siblings. Univariate analysis of the Avoidance ratings showed that the significant interaction effect on this scale was also due to scores given by children, $F(1,102)=7.01, p<.01, \eta$ $=.25$. Again, mean ratings given by males were significantly higher when the sibling was female, $F(1,54)=7.64, p<.01, \eta=.35(M s=6.2[S D$ $=2.70]$ and $4.5[S D=1.99]$, respectively). Female ratings were not significantly different for female and male siblings.

We noted that although the difference was significant only for Avoidance, when the sibling was female, ratings given by males were higher on Unkindness and Avoidance but lower on Empathy and Involvement. Female scores did not show a consistent pattern for dyad composition (see $\mathrm{Ta}$ ble 3$)$.

There were fewer brother-brother $(n=11)$ and more brother-sister dyads $(n=17)$ in the comparison group. The difference between these dyads in the sex commonality analyses of Unkindness and Avoidance suggested that a re-examination of group effects on child scores was necessary. Analyses were undertaken for same-sex and opposite-sex dyads separately, with Sibling Inventory of Behavior ratings given by children as dependent variables and with group and sex as independent factors.

Results were consistent with the previous analysis in finding, for each dyadic composition, a significant effect of group on Unkindness but not on Avoidance or Involvement. In both samesex and opposite-sex dyads, Unkindness was higher in the comparison group than in the group of siblings of children with Down syndrome, both for same-sex dyads, $F(1,46)=8.70, p<.01$, $\eta$ $=.40(M s=9.4,[S D=4.87]$ and $5.3[S D=$ 4.41] for comparison group and siblings of children with Down syndrome, respectively) and for opposite-sex dyads, $F(1,52)=6.75, p<.05, \eta$ $=.34(M s=9.1[S D=3.38]$ and $=6.0[S D=$ 5.13] for comparison group and siblings of children with Down syndrome, respectively). Results, however, were not consistent with the previous analysis of Empathy ratings. As for the dyads combined, there was a significant group effect for 
Table 2. Scores on Sibling Inventory of Behavior Scales

\begin{tabular}{|c|c|c|c|c|c|c|}
\hline \multirow[b]{2}{*}{ Group/scale } & \multicolumn{2}{|c|}{ Father } & \multicolumn{2}{|c|}{ Mother } & \multicolumn{2}{|c|}{ Child } \\
\hline & Mean & $S D$ & Mean & $S D$ & Mean & $S D$ \\
\hline \multicolumn{7}{|c|}{$\begin{array}{l}\text { Siblings in comparison } \\
\text { group }(n=53)\end{array}$} \\
\hline Empathy & 23.4 & 3.78 & 23.6 & 3.84 & 22.8 & 3.96 \\
\hline Involvement & 15.1 & 2.39 & 14.3 & 2.52 & 13.6 & 2.80 \\
\hline Unkindness & 7.4 & 4.59 & 8.7 & 4.92 & 9.3 & 4.05 \\
\hline Avoidance & 4.1 & 1.56 & 4.0 & 1.64 & 5.2 & 2.42 \\
\hline \multicolumn{7}{|c|}{$\begin{array}{l}\text { Siblings of child with } \\
\text { Down syndrome }(n=54)\end{array}$} \\
\hline Empathy & 23.5 & 4.04 & 24.5 & 4.69 & 24.7 & 4.36 \\
\hline Involvement & 14.2 & 2.63 & 13.9 & 2.57 & 14.2 & 2.59 \\
\hline Unkindness & 6.3 & 4.17 & 7.1 & 5.43 & 5.6 & 4.74 \\
\hline Avoidance & 4.5 & 2.00 & 4.4 & 1.77 & 5.4 & 2.45 \\
\hline \multicolumn{7}{|l|}{ Males $(n=56)$} \\
\hline Empathy & 22.8 & 3.92 & 23.2 & 4.34 & 23.1 & 4.40 \\
\hline Involvement & 14.5 & 2.54 & 14.2 & 2.56 & 13.7 & 3.04 \\
\hline Unkindness & 7.8 & 4.54 & 8.5 & 5.30 & 7.6 & 4.94 \\
\hline Avoidance & 4.3 & 1.92 & 4.2 & 1.81 & 5.4 & 2.52 \\
\hline \multicolumn{7}{|l|}{ Females $(n=51)$} \\
\hline Empathy & 24.3 & 3.75 & 24.9 & 4.11 & 24.5 & 4.03 \\
\hline Involvement & 14.8 & 2.56 & 14.0 & 2.53 & 14.1 & 2.28 \\
\hline Unkindness & 5.7 & 4.00 & 7.2 & 5.11 & 7.2 & 4.60 \\
\hline Avoidance & 4.3 & 1.67 & 4.2 & 1.60 & 5.3 & 2.34 \\
\hline
\end{tabular}

dyads of the same sex, $F(1,46)=8.61, p<.01$, $\eta=.40$, with lower scores for the comparison group $(M s=22.4[S D=3.91]$ and $25.5[S D=$ 3.05] for comparison group and siblings of children with Down syndrome, respectively). The effect was not significant for dyads of the opposite sex.

\section{Telephone Reports}

Child interactions with sibling and parents. Telephone data were incomplete for two families, one in each group, and the following analysis is based on a reduced sample. Correlations were significant at the .01 level between positive interactions with sibling and Sibling Inventory of Behavior scores for Involvement, $r=.38$, and Empathy, $r=.31$. Scores for children's positive interactions were analyzed as three repeated measures, with group and sex as independent factors. The only significant effect was the interaction between group and measure (interactions with child, mother, father), $F(2$,
$202)=6.49, p<.01$. Follow-up testing found a trend toward more positive interactions between child and sibling if the sibling were a child with Down syndrome, $p=.09$. Positive interactions were then examined for sex and sex commonality effects. There was a significant interaction between sex commonality and measure, $F(2,202)=$ 4.03, $p<.05$. Univariate analysis revealed that this was due to the effect of sex commonality on interactions with siblings, $F(1,101)=9.05, p<$ .01 . There were more positive interactions between same-sex than opposite-sex siblings $(M \mathrm{~s}=$ $11.9[S D=4.7]$ and $8.9[S D=5.4]$, respectively).

Over the 4 days, a negative interaction with the father was reported by $40 \%$ of the children, with the mother by $61 \%$, and with the sibling by $74 \%$. Because of the skewed distributions, a log transformation was used in a MANOVA analysis of the effects of group and sex on negative interactions. No significant effects were found. Negative interactions were then examined for sex com- 
Table 3. Child Scores on Sibling Inventory of Behavior (SIB) Scales and Dyad Composition (Sibling as Rater)

\begin{tabular}{|c|c|c|c|c|c|c|c|c|}
\hline \multirow[b]{2}{*}{ SIB scale } & \multicolumn{2}{|c|}{ Brother-brother } & \multicolumn{2}{|c|}{ Brother-sister } & \multicolumn{2}{|c|}{ Sister-sister } & \multicolumn{2}{|c|}{ Sister-brother } \\
\hline & Mean & $S D$ & Mean & $S D$ & Mean & $S D$ & Mean & $S D$ \\
\hline Empathy & 24.3 & 3.77 & 22.0 & 4.71 & 24.0 & 3.82 & 24.9 & 4.23 \\
\hline Involvement & 14.7 & 3.18 & 12.7 & 2.59 & 14.3 & 2.01 & 14.0 & 2.53 \\
\hline Unkindness & 6.4 & 5.20 & 8.8 & 4.49 & 8.0 & 4.82 & 6.5 & 4.36 \\
\hline Avoidance & 4.5 & 1.99 & 6.2 & 2.70 & 5.6 & 2.41 & 5.0 & 2.28 \\
\hline
\end{tabular}

monality effects, and a significant effect was found for the interaction between sex and sex commonality. Univariate analysis showed that this was mainly due to children's reports, $F(1$, $101)=12.41, p<.01, \eta=.33$. Females reported more negative interactions with same-sex siblings than did males $(M \mathrm{~s}=3.6[S D=2.9]$ and $1.5[S D$ $=2.1]$, respectively), but males reported more negative interactions with opposite sex siblings than females $(M s=3.4[S D=3.2]$ and $1.8[S D$ $=2.5]$, respectively). Negative interactions with siblings were significantly associated with Sibling Inventory of Behavior scores for Unkindness, $r s$ $=.36, .29$, and .25 for child, mother, and father ratings, respectively.

\section{Caregiving}

Pearson correlation between caregiving scores given by mothers and children was strong, $r=$ $.76, p<.01$, so only child scores are considered in the following analyses. With significance level at $p$ less than .01 for 6 comparisons, caregiving and daily interactions were significantly associated only with respect to children's positive interactions with siblings, $r=.55$. Correlation with CA was not significant. Correlations between children's caregiving and their own Sibling Inventory of Behavior ratings were significant for Empathy, Involvement, and Avoidance, $r s=.30, .30$, and -.27 , respectively. The association with caregiving was also significant for Empathy ratings by mothers, $r=.28$, with a trend to significance for fathers, $r=.23$. We used an ANOVA to investigate the effects of group and sex on caregiving. Group was significant, $F(1,101)=12.61, p<$ $.001, \eta=.33$, but Sex and Group $\times$ Sex were not. Children who had a sibling with Down syndrome had higher scores than did those in the comparison group (see Table 4).

To determine whether children of older relative age provided more care to their sibling re- gardless of group, or whether there was a group interaction, indicating a possible role-crossover for children with Down syndrome, we conducted an ANOVA with group and relative age as independent measures. Group was again significant as was relative age, $F(1,101)=23.39, p<.001, \eta=.43$, but the interaction between relative age and group was not. The children of older relative age had higher mean scores than did the younger children (see Table 4).

Previous analyses showed that if children had a sibling with Down syndrome, they were more involved in caregiving, especially if older than their sibling. Only 3 of 53 children in this group were given a score of zero for caregiving over 4 days of telephone interviews, and they were all younger than their sibling with Down syndrome. However, almost one fifth of the comparison group, 8 younger than their sibling and 2 older, were given zero scores.

High scores (upper quartile for each group) were examined regarding birth order. In the comparison group, 11 children ( 6 females, 5 males) were first-born and in the siblings of children with Down syndrome, 7 (3 females, 4 males) were firstborn. The proportion of first born (11:19) who were in the upper quartile was higher than the proportion of other birth orders (2:33) for the comparison group, $\chi^{2}(1, N=52)=14.6, p<$ .001 , but not the other group.

\section{Chores}

Correlation between chores reported by mothers and children was .61, $p<.01$. There were also associations with the child's age, $r=.23, p<$ .05 , and $.26, p<.01$, for mother and child. When chores reported by children were correlated with their reports of interactions with sibling and parents, significance level $p<.01$, the strongest associations were between chores and positive interactions with mothers and fathers, $r s=.46$ and 
Table 4. Number of Daily Caregiving Actions and Chores by Group and Relative Age

\begin{tabular}{|c|c|c|c|c|c|c|}
\hline \multirow[b]{2}{*}{ Sibling group } & \multicolumn{3}{|c|}{$\begin{array}{l}\text { Mother reports } \\
\text { caregiving }\end{array}$} & \multicolumn{3}{|c|}{ Child reports caregiving } \\
\hline & Mean & $S D$ & Range & Mean & $S D$ & Range \\
\hline Siblings of children in comparison group $(n=53)$ & 0.6 & 0.7 & $0.0-2.7$ & 0.6 & 0.6 & $0.0-2.8$ \\
\hline Older child in dyad $(n=28)$ & 0.9 & 0.8 & $0.0-2.7$ & 0.9 & 0.7 & $0.0-2.8$ \\
\hline Younger child in dyad $(n=25)$ & 0.2 & 0.2 & $0.0-0.8$ & 0.3 & 0.3 & $0.0-0.8$ \\
\hline Siblings of children with Down syndrome $(n=54)$ & 1.1 & 0.9 & $0.0-3.2$ & 1.1 & 0.9 & $0.0-4.2$ \\
\hline Older child in dyad $(n=28)$ & 1.5 & 1.0 & $0.2-3.2$ & 1.5 & 1.0 & $0.0-4.2$ \\
\hline Younger child in dyad $(n=26)$ & 0.8 & 0.6 & $0.0-2.2$ & 0.8 & 0.6 & $0.0-2.0$ \\
\hline
\end{tabular}

.40 , respectively. There were lower but significant associations with sibling positive interactions, $r=$ .26 , and negative interactions with mother, $r=$ .27. When chores reported by mothers were correlated with children's daily interactions, the only significant association was between chores and negative interactions with mother, $r=.31$. Chores reported by children were not significantly associated with their own or parental Sibling Inventory of Behavior scores. Chores reported by mothers were not significantly associated with child or mother Sibling Inventory of Behavior scores but were for father ratings for Empathy, $r=.30, p<$ .01 , and a trend for Involvement, $r=.24, p<$ .05 .

Scores were then used in a MANOVA as repeated measures, with group and sex as independent measures. There were no significant group, sex, or interaction effects. Another MANOVA with group and relative age as independent variables also failed to find significant effects. (See Table 4 for chore values.) There was no difference between groups regarding the number of firstborn children or sisters who scored in the upper quartile.

\section{Discussion}

Correlations between Sibling Inventory of Behavior ratings suggest that parents and children were more likely to agree on positive aspects of the relationship. Fathers tended to have lower agreement than mothers with children, possibly because fathers do not see negative interactions often enough. The lowest association concerned Avoidance. Parents were inaccurate in interpreting their child's feelings of avoidance. These may be less overtly expressed than an unkind or hurtful action but may nevertheless influence sibling re- lationships. Unkindness was perceived similarly by parents and children and associated with negative sibling interactions. In contrast, Avoidance was not associated with either positive or negative sibling interactions. There was, however, a negative association between Avoidance and activities that involved sibling caregiving.

Siblings of children with Down syndrome did not differ significantly from other children regarding many aspects of their sibling relationships. When differences were found, group effects were in the direction of more positive interactions for siblings of a child with Down syndrome. During telephone interviews, there was a trend for these children to report more positive sibling interactions. Unkindness ratings on the Sibling Inventory of Behavior were significantly lower, and same-sex dyads gave higher Empathy ratings.

Telephone reports of sibling interactions between sisters agreed with the sex commonality principle reported by Akiyama et al. (1996). Females reported more positive and more negative interactions with a sister than a brother. Males reported more positive but fewer negative sibling interactions with a brother than a sister. Brother (rater)-sister dyads also had higher Avoidance scores than other dyads. Indications of avoidance suggest that negativity in these sibling interactions may be related to embarrassment or discomfort. Several studies have reported that males develop closeness through childhood from shared interests and activities (Floyd, 1995). It has been speculated that friction during childhood between older brothers and younger sisters may stem from greater discomfort in boys with regard to cross-gender activities (Rust et al., 2000).

The only findings supporting the femaleness principle were lower ratings of Unkindness given by fathers to females. Fathers may have a more 
Table 4. Extended

\begin{tabular}{ccccccc}
\multicolumn{3}{c}{ Mother reports chores } & & \multicolumn{3}{c}{ Child reports chores } \\
\cline { 1 - 3 } \cline { 5 - 6 } Mean & $S D$ & Range & & Mean & SD & Range \\
\hline 6.6 & 2.1 & $1.5-12.0$ & & 7.3 & 2.7 & $2.2-16.0$ \\
7.1 & 1.6 & $4.0-12.0$ & & 7.7 & 2.9 & $4.2-16.0$ \\
6.0 & 2.4 & $1.5-11.5$ & & 6.9 & 2.5 & $2.2-11.8$ \\
5.9 & 2.3 & $1.5-10.5$ & & 6.3 & 2.7 & $2.0-13.0$ \\
6.4 & 2.6 & $2.0-10.0$ & & 6.5 & 2.7 & $2.2-13.0$ \\
5.5 & 1.9 & $1.5-10.5$ & 6.1 & 2.7 & $2.0-11.0$ \\
\hline
\end{tabular}

stereotyped view of gender and less day-to-day experience with actual behaviors. Despite these perceptions of female kindness, femaleness was not strongly related to provision of support.

Sisters did not take on more caregiving than brothers, whether or not their sibling had Down syndrome. Children provided more care to siblings with Down syndrome but also more care to a sibling who was the younger child in the dyad, regardless of group. The group difference is compatible with reports by McHale and Gamble (1989) and Stoneman et al. (1991) but contrasts with these studies in not finding a gender difference. It does, however, support our previous study (Cuskelly \& Gunn, 1993) and suggests possible differences across countries or cohort differences regarding gender roles.

There was no indication of a "role crossover" effect, but the younger child in a dyad was more likely to show at least one sign of caregiving if the older sibling had Down syndrome. Stoneman et al. (1991) reported that younger siblings of children with mental retardation provided more caregiving than did their peers, with the extent of caregiving depending on the severity of the sibling's disability. Because the children with Down syndrome were in the moderate range of disabilities, the extent of caregiving by a younger sibling is likely to be attenuated. The strong relationship between positive but not negative interactions with sibling and caregiving scores suggests that care was regarded in a positive light. If it had been resented, an increase in negative interactions could be expected.

First-born children or older sisters who had a sibling with Down syndrome were not given a greater share of family responsibilities, whether caregiving for the sibling or contributing to family chores. Although siblings who provided most caregiving to children with Down syndrome came from a range of birth orders, comparison children with highest caregiving scores were predominantly first-born. Parents of children with Down syndrome would be aware of well-promulgated older hypotheses about the burden of care that can fall on first-born children or older sisters. This is not so likely to be a factor influencing the perspectives of parents in the comparison group.

Older children assumed more household responsibility, but siblings of children with Down syndrome did not undertake more than their peers. The number of chores reported by children was strongly associated with positive interactions with parents. On the other hand, chores reported by mothers were strongly associated with children's negative interactions with mothers. This possibly reflects a mother's role in monitoring chores because often children do not complete these tasks without active intervention from a parent.

Although both parents and children saw more empathy in the sibling relationship for children who undertook more caregiving, a connection between empathy and chores appeared only in father ratings. Fathers may be guided by impressions of overall helpfulness of a child as a family member rather than by specific child behaviors directed to a sibling. It is likely that mothers and children can provide more specific information because they have more regular day-to-day experience with relationships between siblings.

Overall, results of this study suggest a sibling relationship not damaged by Down syndrome in one child. The sample, however, represented intact, mainly middle-class families. As in other studies of disability, difficulties in recruiting a large sample limit analyses of more interactive dimensions of a sibling relationship. Further study of opposite-sex relationships with larger cell sizes would be especially valuable.

\section{References}

Akiyama, H., Elliot, K., \& Antonucci, T. C. (1996). Same-sex and cross-sex relationships. Journals of Gerontology: Series B in Psychological Sciences and Social Sciences, 51B(6), 375-382.

Australian Bureau of Statistics. (2001). Australian social trends 1996. Canberra: Author.

Bigby, C. (1996). Transferring responsibility. Journal of Intellectual and Developmental Disability, 21, 295-312. 
Cicirelli, V. G. (1996). Sibling relationships in middle and old age. In G. H. Brody (Ed.), Sibling relationships: Their causes and consequences (pp. 47-73). Norwood, NJ: Ablex.

Cuskelly, M., \& Gunn, P. (1993). Maternal reports of behavior of siblings of children with Down syndrome. American Journal on Mental Retardation, 97, 521-529.

Damiani, V. B. (1999). Responsibility and adjustment in siblings of children with disabilities: Update and review. Families in Society: The Journal of Contemporary Human Services, 80, 34-41.

Daniel, A. (1983). Power, privilege and prestige. Melbourne, Australia: Longman-Cheshire.

Epkins, C. C., \& Dedman, A. M. M. (1999). An initial look at sibling reports on children's behavior: Comparisons with children's self-reports and relations with siblings' self-reports and sibling relationships. Journal of Abnormal Child Psychology, 27, 371-381.

Floyd, K. (1995). Gender and closeness among friends and siblings. Journal of Psychology, 129, 193-202.

Gath, A., \& McCarthy, J. (1996). Families and siblings: A response to recent research. In B. Stratford \& P. Gunn (Eds.), Nezw approaches to Down syndrome (pp. 361-368). London: Cassell.

McHale, S. M., \& Gamble, W. C. (1989). Sibling relationships of children with disabled and nondisabled brothers and sisters. Developmental Psychology, 25, 421-429.

O’Connor, W. A., \& Stachowiak, J. (1971). Patterns of interaction in families with low adjusted, high adjusted, and mentally retarded members. Family Process, 10, 229-241.

Orsmond, G. I., \& Seltzer, M. M. (2000). Brothers and sisters of adults with mental retardation: Gendered nature of the sibling relationship. American Journal on Mental Retardation, 105, 486-508.

Rust, J., Golombok, S., Hines, M., Johnston, K., Golding, J., \& The ALSPAC Study Team. (2000). The role of brothers and sisters in the gender development of preschool children. Journal of Experimental Child Psychology, 77, 292-303.

Schaefer, E., \& Edgerton, M. (1981). The Sibling Inventory of Behavior. Unpublished manuscript, University of North Carolina, Chapel Hill.

Seltzer, G. B., Begun, A., Seltzer, M. M., \& Krauss, M. W. (1991). Adults with mental retardation and their aging mothers: Impacts of siblings. Family Relations, 40, 310-317.

Steele, J. (1996). Epidemiology: Incidence, prevalence and size of the Down's syndrome population. In B. Stratford \& P. Gunn (Eds.), New approaches to Down syndrome (pp. 45-72). London: Cassell.

Stoneman, Z. (1989). Comparison groups in research on families with mentally retarded members: A methodological and conceptual review. American Journal on Mental Retardation, 94, 195-215.

Stoneman, Z., Brody, G. H., Davis, C. H., Crapps, J. M., \& Malone, D. M. (1991). Ascribed role relations between children with mental retardation and their younger siblings. American Journal on Mental Retardation, 95, 537-550.

Received 9/13/01, accepted 1/7/03.

Editor-in-charge: William E. MacLean, Jr.

Aspects of this study were presented at the 11th World Congress of International Association for the Scientific Study of Intellectual Disability, Seattle, 2000. The authors acknowledge the contribution of the families in the study, who were so patient and helpful; the Queensland Down Syndrome Association for its assistance in the search for participants; and the two reviewers who contributed greatly to the paper in its final form. Requests for reprints should be sent to Monica Cuskelly, Fred and Eleanor Schonell Special Education Research Centre, University of Queensland, Queensland, 4072, Australia. E-mail: m.cuskelly@mailbox.uq.edu.au. 